\title{
Distribution of Salmonella enterica isolates from human cases in Italy, 1980 to 2011
}

C Graziani¹, L Mughini-Gras¹, S Owczarek², A M Dionisi², I Luzzi², L Busani (luca.busani@iss.it)1

1. Istituto Superiore di Sanità, Department of Veterinary Public Health and Food Safety, Rome, Italy

2. Istituto Superiore di Sanità, Department of Infectious, Parasitic and Immuno-Mediated Diseases, Rome, Italy

Graziani C, Mughini-Gras L, Owczarek S, Dionisi AM, Luzzi I, Busani L. Distribution of Salmonella enterica isolates from human cases in Italy, 1980 to 2011 . Euro Surveill. 2013;18(27):pii=20519. Available online: http://www.eurosurveillance.org/ViewArticle.aspx?Articleld=20519

We describe trends of Salmonella enterica serovars isolated from humans in Italy from January 1980 to December 2011. A total of 229,279 Salmonella isolates were reported during this period. Serovars Enteritidis, Typhimurium, Infantis, Derby, 4,[5],12,:i:-, and Napoli accounted for 135,783 (59\%) of these isolates. Temporal trends from 2000 to 2011 varied by serovar: Enteritidis and Infantis decreased significantly (with a mean of $-3.0 \%$ and $-2.8 \%$ isolates per year, respectively, p<0.001); Typhimurium remained stable; while 4,[5],12:i:-, Derby and Napoli increased significantly (+66.4\%, p<0.001; $+8.1 \%$, p<0.001; and $+28.2 \%$, p<0.05, respectively). Since 2000 , Enteritidis fell consistently below Typhimurium, which is the most reported serovar in Italy in contrast to the international situation where Enteritidis still ranks at the top despite its significant decrease. Most serovars showed a marked seasonality, increasing over the summer months and peaking in August/September. Typhimurium, 4,[5],12:i:-, and Napoli were most likely to be isolated from children, whereas Enteritidis, Derby, and Infantis from adults. We conclude that the applied control measures are not equally efficient against the considered Salmonella serovars and that sources of infection other than those of Enteritidis (laying hens and eggs) have become increasingly important. Further investigations on the emerging serovars and on the causes related to their emergence are needed to define and implement newly tailored control measures.

\section{Introduction}

In the European Union (EU), Salmonella infection is the primary cause of confirmed foodborne outbreaks and the second most reported zoonosis, behind Campylobacter infection [1]. Recently it has been estimated that approximately 6.2 million cases of human salmonellosis occur in the EU general population each year, 298,000 of which in Italy (approximately 60 million population) [2].

More than 2,500 serovars of Salmonella enterica have been described [3]. Although virtually all these serovars are capable of infecting humans, most human infections are caused by a limited number of serovars. S. Enteritidis and S. Typhimurium are among the serovars most frequently associated with human illness in the EU, accounting for up to $68 \%$ of confirmed human cases identified at serovar level [1]. Poultry, and particularly laying hens for table egg production, have long been identified as the primary source of human $S$. Enteritidis infection, whereas it is widely accepted that human $S$. Typhimurium infection primarily originates from pigs [4].

Salmonella serotyping is an important tool for surveillance purposes that allows for trends to be monitored over space and time. Serotyping is also a useful classification scheme to support the investigation of foodborne outbreaks and the attribution of human cases to different sources of infection and routes of transmission [4].

In Italy, the laboratory-based surveillance system for human Salmonella infections has changed substantially over time to follow the evolution of the surveillance activities for infectious diseases undertaken at the national and international level [5]. The former system was created in 1967 and was based on the Reference Centres for Enterobacteriaceae (RCE) [5,6], which became part of the European Salmonella Network (SALM-NET) project in 1992 [5]. In 1997, SALM-NET was further changed into the Enteric Pathogen Network (ENTER-NET) [7]. Italy's ENTER-NET (IT-ENTER-NET) is a passive, laboratory-based surveillance system for enteropathogens based on a network of more than 140 clinical microbiology diagnostic laboratories covering about $65 \%$ of the Italian territory and is complementary to the Italian National Surveillance System for Infectious Diseases (SIMI) [8,9]. Since October 2007, the European ENTER-NET has been coordinated by the European Centre for Disease Prevention and Control (ECDC), European Food- and Waterborne Disease and Zoonoses Surveillance Network (FWD-Net) [10]. 
In Italy, IT-ENTER-NET collects basic microbiological information (at least the serovar) on Salmonella isolates from human cases each year. These isolates correspond to approximately $50 \%$ of the total number of human salmonellosis cases notified to the SIMI [11]. Since 2002, the IT-ENTER-NET laboratories are also invited to submit $S$. Enteritidis and S. Typhimurium isolates to the Istituto Superiore di Sanità (Italian National Institute of Health) for phage and molecular typing and antimicrobial susceptibility testing.

The aim of this study was to describe the distribution of Salmonella serovars isolated from humans in Italy from January 1980 to December 2011, with a focus on the six most frequently reported serovars.

\section{Method}

Data of Salmonella isolates from human cases were obtained from different laboratory-based surveillance systems depending on the considered time period. Data from 1980 to 1992 were obtained from published statistics of the RCE [6]. Data from 1993 to 1997 were obtained from the SALM-NET records and those from 1998 to 2011 from IT-ENTER-NET (http://www.iss.it/ salm/?lang=1\&id=1\&tipo=4). In all of these three systems, the common case definition was 'an isolate of Salmonella enterica with identified serovar from a human specimen'.

For the purposes of this study, a minimum set of comparable information about each serotyped isolate was collected, including the patient sex, age and residence location, the laboratory that reached the microbiological diagnosis and the date of isolation thereof. This set of information was not systematically collected and made available before 2000, when only the serovar and the year of isolation were available.

A data set including Salmonella isolates of the whole study period (1980-2011) was created by merging the data obtained from the three systems (RCE, SALM-NET, and IT-ENTER-NET). This data set contained 254,418 records (i.e. isolates) with information on the serovar and date of isolation.

Another data set that included the isolates collected by IT-ENTER-NET from 2000 to 2011 (56,546 records) was created. This data set contained a number of duplicate entries, i.e. different isolates from a same case (because of the follow-up of patients with Salmonella infection after the first isolation) that were not always indicated. Therefore, 24,492 duplicate entries for an isolate that matched on serovar, laboratory reaching the microbiological diagnosis, and date of birth of the patient within the same or the consecutive month of isolation were discarded. Moreover, during the study period there were 2,122 cases related to 1,475 outbreaks (subjects tested within the framework of 'epidemiological investigation' in the IT-ENTER-NET data set) so we also discarded 647 outbreak-related entries, choosing only one isolate from each outbreak.
The resulting data set included a total 31,407 records. Data management procedures were performed using ACCESS, version 2002 (Microsoft, Redmond, USA).

Data analysis focussed on the six most frequently reported serovars in the whole study period. The distribution of isolates by year was examined from 1980 to 2011 , whereas the distribution by sex, age group $(\langle 1,1-5,6-14,15-64$, and $>65$ years) and month of isolation (January-December) was examined using the 2000-2011 data set. Mean annual isolation rates per 100,000 population were calculated by serovar, sex, age group, and province of residence standardised to the 2008 Italian reference population provided by the Italian National Institute of Statistics (ISTAT) (http:// demo.istat.it/).

The inter-annual trend in the number of isolates from 2000 to 2011 was tested for statistical significance using the Cuzick's test for trend [12] (alpha: 0.05). Data analysis was performed using Epilnfo2000, version 3.3.1 (Centers for Disease Control (CDC), Atlanta, USA), and STATA, version 11.2 (StataCorp, College Station, USA).

Shapefile of Italy with provincial administrative boundaries was obtained from the ISTAT (ED-1950-UTM coordinate system, zone $32 \mathrm{~N}$ ). Mean annual isolation rates per 100,000 population were presented using a choropleth map (with 4 classes determined according to Jenks' natural breaks method) in ArcGis, version 9.0 (ESRI, Redlands, USA).

\section{Results}

\section{Inter-annual trends}

After exclusion of duplicate and outbreak-related entries (if more than one per outbreak), a total of 229,279 Salmonella isolates were reported from 1980 to 2011. The annual number of isolates decreased from an annual mean of 10,286 isolates in the period from 1980 to 1995 to an annual mean of 4,043 isolates in the time between1996 and 2011, with a more marked reduction from the year 2000 onwards $(2,618$ isolates on mean per year).

During the whole study period, the top six reported serovars were $S$. Enteritidis (57,499 isolates; $25.1 \%$ of the total number of Salmonella isolates; mean isolation rate: 2.99 isolates per 100,000 population/year), S. Typhimurium $(56,671 ; 24.7 \% ; 2.95$ per 100,000 population/year), S. Infantis (10,114; 4.4\%; 0.53 per 100,000 population/year), S. Derby $(8,250 ; 3.6 \%$; 0.43 per 100,000 population/year), S. 4,[5],12,:i:- $(2,381 ; 1.0 \%$; 0.12 per 100,000 population/year) and S. Napoli (868; $0.4 \%$; 0.04 per 100,000 population/year). The other serovars accounted cumulatively for 93,496 isolates (40.8\%; 4.87 per 100,000 population/year) (Figure 1).

S. Typhimurium was the predominant serovar from 1980 to 1988 , but in $1989 \mathrm{~S}$. Enteritidis overtook S. 


\section{FIGURE 1}

Temporal trend of the top six reported Salmonella enterica serovars, Italy, 1980-2011 (n=229,279)
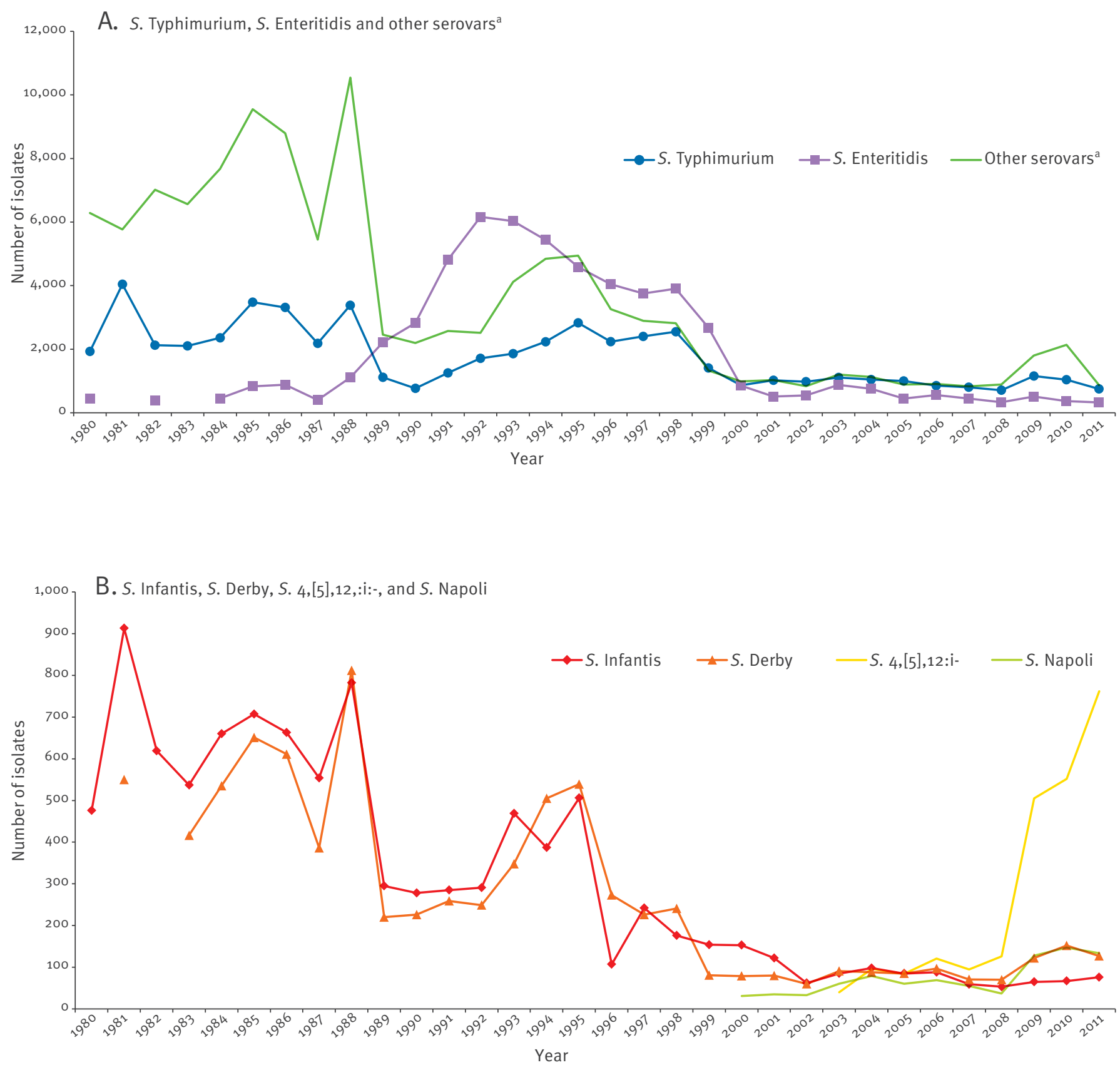

Some points in the charts representing the annual number of isolates for the S. enterica serovars Enteridis (panel A) and Derby (panel B) stand alone and are not included in the curve relating the annual number of isolates throughout the study period. This is because these two serovars were not reported for all years during the period up to the mid-1980s, resulting in missing data in the time series.

${ }^{a}$ Other serovars include all serovars other than S. Enteritidis and S. Typhimurium. 
Median number of isolates of the top six reported Salmonella enterica serovars by month of isolation, Italy, 2000-2011 $(n=31,407)$

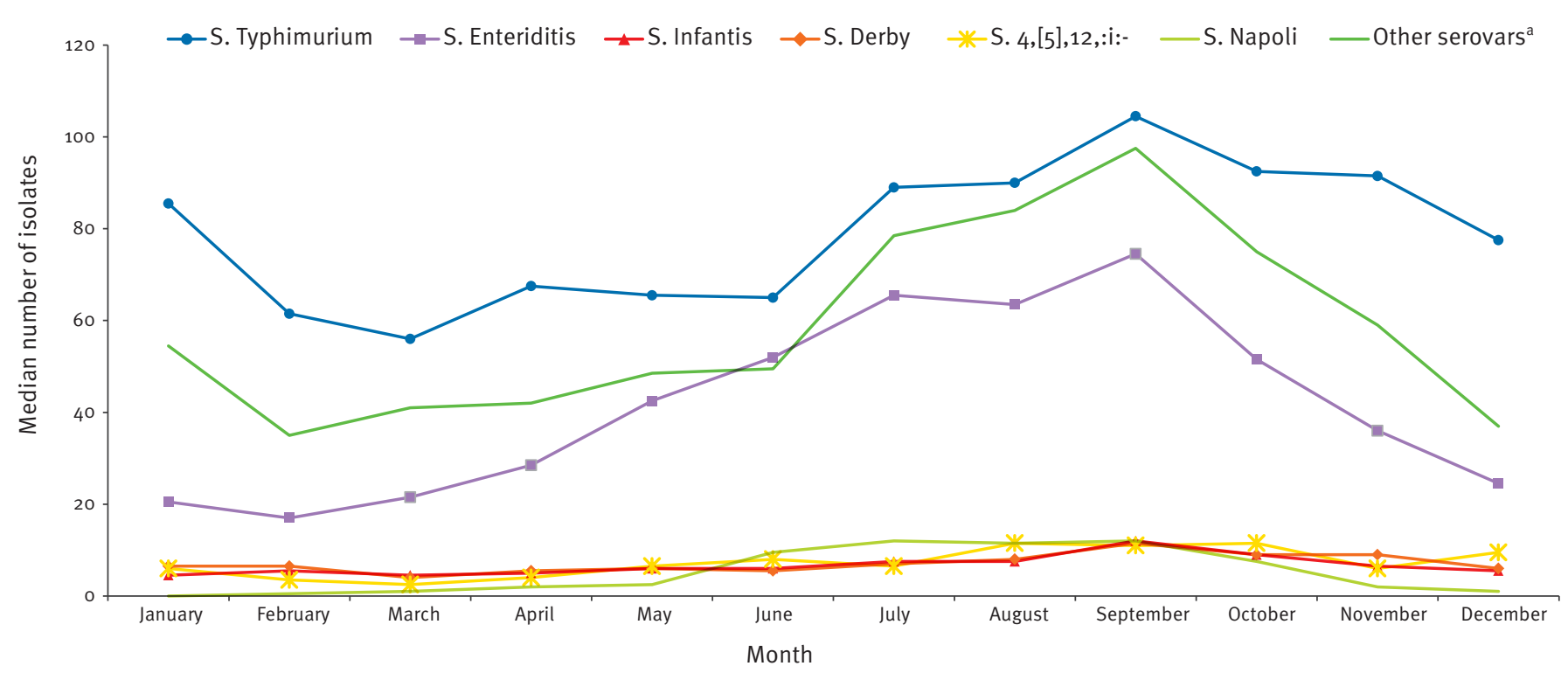

a Other serovars include all serovars other than S. 4,[5],12,:i:-, S. Derby, S. Enteritidis, S. Infantis, S. Napoli and S. Typhimurium.

Typhimurium and dramatically increased in the following years, reaching a peak in 1992. Since then, S. Enteritidis started decreasing, and from 2000 onwards $S$. Typhimurium returned to being the predominant serovar (Figure 1).

S. Infantis and S. Derby alternated as having the position of the third most frequently reported serovar during the whole study period (Figure 1). A decrease in the annual number of isolates for both serovars occurred from the mid-1990s, and from 2002 to 2008 the respective annual number of isolates remained below 100 isolates per year. Starting from 2009, however, the number of isolates of $S$. Derby per year increased and approximately doubled the number of $S$. Infantis isolates.

In 2000 and 2003, S. Napoli and S. 4,[5],12,:i:emerged, respectively. S. Napoli increased from 31 isolates in 2000 to 134 isolates in 2011. S. 4,[5],12,:i:- was isolated for the first time in Italy in 2003 with 40 isolates $(1.3 \%$ of the total number of isolates of that year). Since then, it increased steadily, reaching 762 isolates (39.1\%) in 2011.

From 2000 to 2011, a significantly increasing temporal trend in the number of isolates was observed for $S$. Derby (mean of $+8.1 \%$ isolates per year, p<0.001; mean isolation rate: 0.16 isolates per 100,000 population/year), S. Napoli (+28.2\%, $p=0.032 ; 0.22$ per 100,000 population/year) and S. 4,[5],12:i:- (+66.4\%, p<0.001; 0.33 per 100,000 population/year), whereas a significantly decreasing temporal trend was observed for S. Infantis (-2.8\%, p<0.001; 0.14 per 100,000 population/year) and S. Enteritidis (-3.0\%, p<0.001; 0.91 per 100,000 population/year) isolates. $S$. Typhimurium isolates did not show any significant trend from 2000 to 2011 ( $p=0.11 ; 1.58$ per 100,000 population/year).

\section{Seasonal distribution}

In the period from 2000 to 2011 , the largest proportion of Salmonella isolates was observed in September $(4,025 / 31,407$ cases, $13 \%)$ and the smallest in February $(1,698 / 31,407$ cases, $5 \%)$. The median number of isolates in these two months was 335 and 139 respectively (Figure 2). Although this seasonal pattern was consistent for most serovars, S. Napoli and S. Derby showed slight variations. S. Napoli increased steeply in June (median $=10$ isolates) and peaked in July (median $=$ 12 isolates), remained at high levels until September (median $=12$ isolates) and then decreased rapidly in October (median $=8$ isolates). $S$. Derby peaked in September (median $=12$ isolates) but remained at a high level until November (median $=9$ isolates), when thereafter a stepwise decrease occurred until March, the month for which the median number of isolates was at the lowest (median $=4$ isolates) (Figure 2).

Age and sex distributions

During the period between 2000 and 2011, the highest isolation rate was for children aged one to five years, 
Distribution of the annual isolation rates of the top six reported Salmonella enterica serovars in Italy, by age and sex, Italy, 2000-2011 $(n=31,407)$

\begin{tabular}{|c|c|c|c|c|c|c|c|}
\hline \multirow{2}{*}{ Serovar } & \multicolumn{7}{|c|}{ Annual isolation rates ${ }^{a}$} \\
\hline & o-11 months & $1-5$ years & $6-14$ years & $15-64$ years & $\geq 65$ years & Female & Male \\
\hline S. Typhimurium & 3.95 & $14 \cdot 40$ & 3.24 & 0.43 & 0.77 & 1.42 & 1.71 \\
\hline S. Enteritidis & 2.47 & 6.03 & 1.99 & 0.43 & 0.45 & 0.91 & 0.96 \\
\hline S. 4,[5],12:i:- & 0.69 & 2.36 & 0.58 & 0.06 & 0.16 & 0.23 & 0.27 \\
\hline S. Derby & 0.44 & 0.84 & 0.15 & 0.06 & 0.18 & 0.14 & 0.15 \\
\hline S. Infantis & 0.36 & 0.70 & 0.18 & 0.06 & 0.13 & 0.13 & 0.15 \\
\hline S. Napoli & 0.64 & 1.03 & 0.20 & 0.02 & 0.08 & 0.10 & 0.12 \\
\hline Other serovars & 4.98 & 7.19 & 1.66 & 0.52 & 1.02 & 1.12 & 1.25 \\
\hline Total & 13.54 & 32.54 & 8.01 & 1.60 & 2.80 & 4.06 & 4.62 \\
\hline
\end{tabular}

a The annual isolation rates are the annual number of isolates of each serovar/100,000 population of the age group or sex under consideration.

at 32.54 isolates per 100,000 population/year, followed by infants aged <1 year (13.54 per 100,000 population/year) and children aged six to 14 years (8.01 per 100,000 population/year). In the other age groups, the mean isolation rate was $<3$ isolates per 100,000 population/year. There were no evident differences in isolation rates between males and females (4.62 and 4.06 isolates per 100,000 population/year, respectively) (Table).

Of the total 31,407 isolates reported from 2000 to 2011 , $1,005(3.2 \%)$ were from cases of Salmonella enterica infection aged less than one year, 12,217 (38.9\%) from cases aged one to five years, 5,339 (17.0\%) from cases aged six to 14 years, 8,449 (26.9\%) from cases aged 15 to 64 years, and 4,397 (14.0\%) from cases aged $\geq 65$ years.

Considering the top six reported serovars, $S$. Typhimurium showed the highest isolation rate in all age groups except for cases aged 15 to 64 years, where $S$. Typhimurium and $S$. Enteritidis accounted for the same proportion of isolates $(2,264 / 8,449$ and $2,261 / 8,449 ; 26.8 \%)$. S. Typhimurium accounted for $3,469 / 12,217(28.4 \%)$ and $2,322 / 5,339(43.5 \%)$ of isolates from children aged one to five and six to 14 years, respectively. S. 4,[5],12:i:- had a visibly higher isolation rate than $S$. Derby and $S$. Infantis in cases aged one to five years but not in cases aged 15 to 64 years, where S. 4,[5],12:i:-, S. Derby, and S. Infantis had almost the same isolation rate. Moreover, while $S$. Napoli was the fourth most isolated serovar in cases aged $\leq 14$ years, it was the least represented in those aged $>14$ years.

\section{Spatial distribution}

Figure 3 presents the distribution at the province level of the mean annual isolation rate per 100,000 population of the top six reported serovars (2000 to 2011). The highest isolation rates were observed in the northern provinces of the country, particularly in the provinces of Sondrio, Trento, and Varese, whereas the southern provinces showed considerably lower isolation rates. Such spatial distribution was also observed in the isolation rate of the different serovars.

\section{Discussion}

Evidence that human salmonellosis in Italy has decreased since the late 1990 s has previously been provided through the analysis of cases notified to the SIMI [9]. This study shows that, since 2000, the decrease has concerned only specific serovars, namely S. Enteritidis and S. Infantis, whereas other serovars have emerged (S. 4,[5],12:i:-, S. Derby, and S. Napoli) or remained fairly stable (S. Typhimurium).

After the global emergence of $S$. Enteritidis in the late 1980 s that apparently filled the ecological niche vacated by the eradication of $S$. Gallinarum from poultry [13], a sustained decrease in the number of human $S$. Enteritidis infections was observed globally starting from the late 1990 [4,14-17]. Several factors, including the implementation of new on-farm control measures against Salmonella in poultry (e.g. the introduction of live vaccines), improved hygiene and education of consumers and food-workers, have probably contributed to this decrease, at least in the EU $[1,4]$ and in the United States $[15,18]$. In 1992, the European Parliament issued a directive (Council Directive 92/117/EEC) [19] establishing measures for protection against specified zoonotic agents in animals and foods of animal origin. This Directive proposed that the EU Member States establish monitoring systems and control measures in poultry breeding flocks. In 2003, to enforce these measures, the European Parliament and the EU Council introduced the Regulation No. 2160/2003 [20] to ensure that proper and effective measures were undertaken to control Salmonella at all relevant stages of production, processing, and distribution of poultry 


\section{FIGURE 3}

Province-level maps of the mean annual isolation rates per 100,000 population of Salmonella enterica, Italy, 2000-2011 $(\mathrm{n}=31,407)$

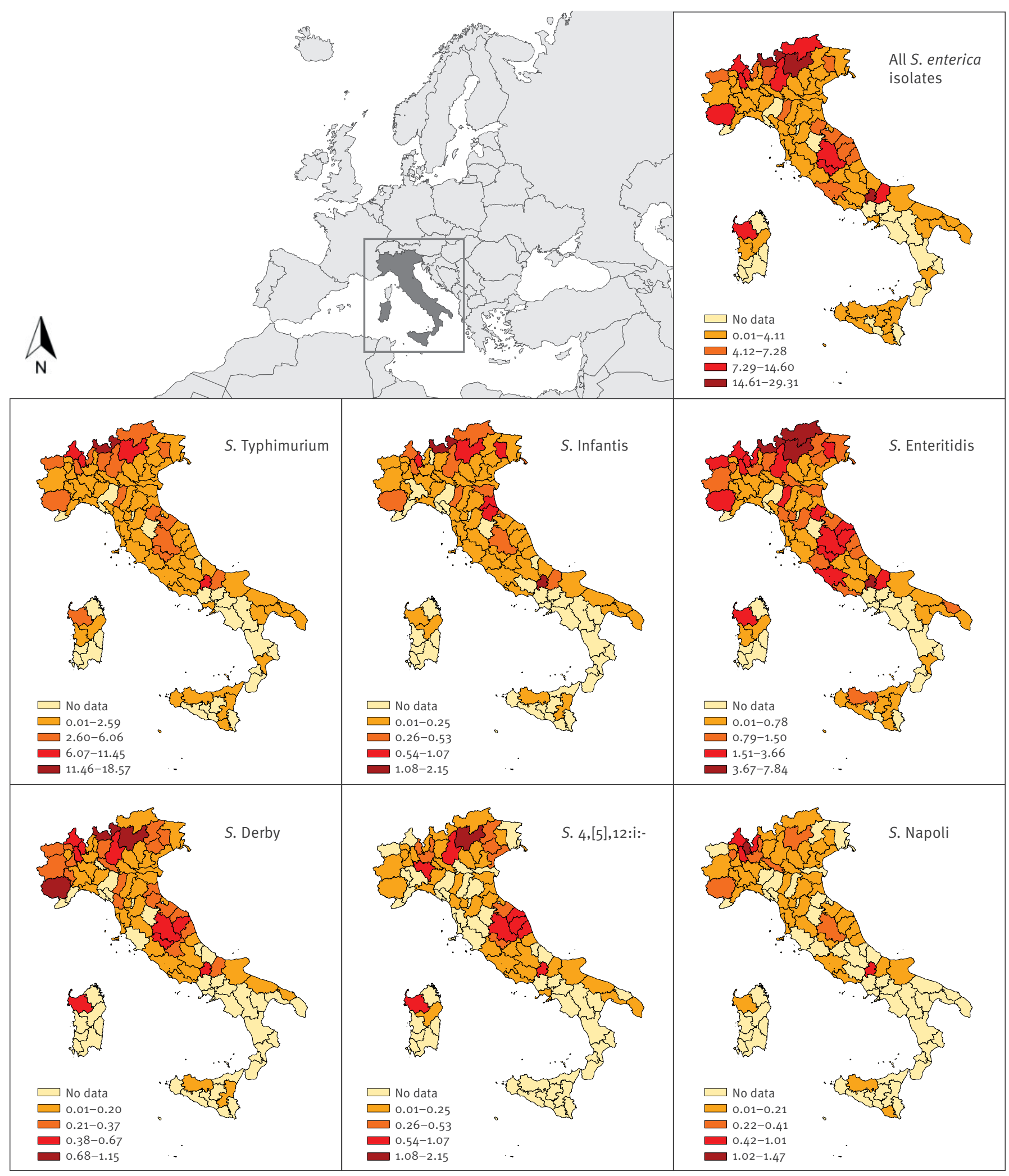


products. The observed decrease of human cases of $S$. Enteritidis suggests that these measures have succeeded in reducing the burden of human $S$. Enteritidis infection.

We observed a peculiar profile of serovars in Italy, as $S$. Enteritidis fell consistently below $S$. Typhimurium since 2000, whereas in most other EU countries, despite the significant decrease of $S$. Enteritidis, $S$. Typhimurium has never became the most reported serovar, at least until the second half of the first decade of the 2000 [17]. This is particularly evident in the EU, where in this period few countries in addition to Italy have experienced this shift in the dominant serovar, i.e. Belgium, Denmark and France [4]. In 2011, $S$. Typhimurium had been predicted to become the most common serovar in England and Wales by 2012 as a result of the decrease of $S$. Enteritidis [21].

Given the distribution of serovars from humans and animal sources in the period from 2007 to 2009 , it has been estimated that pig and pork products are the most important source of human salmonellosis in Italy, accounting for $73 \%$ of human infections [4]. This is in line with our results, as pigs constitute in fact the most important reservoir for S. Typhimurium [4].

As laying hens are the most likely source of human S. Enteritidis infection in Europe [4], the drastic decrease of human cases of $S$. Enteritidis in Italy may be explained, to some extent, by the structure of the Italian poultry industry (which is largely developed through the vertical integration system) and by the fact that poultry meat and table egg production in Italy is self-sufficient to meet the internal market demand. Vertical integration means that all major stages of poultry production (e.g. feed mills, breeder farms, hatcheries, grower farms and processors) are parts of a streamlined poultry production system, usually united through a common owner. This enables companies to harmonise biosecurity measures, housing technologies, feeding regimens, vaccination schemes and testing protocols among farms, so as to control the (microbiological) quality of both input and output products. Moreover, since 2003, the level of biosecurity and hygiene practices in the Italian poultry industry have greatly been enhanced to address the legal requirements provided for the control of avian influenza epidemics [22]. These improvements may have had a particularly significant impact on the effectiveness of the applied control measures against $S$. Enteritidis in the Italian poultry industry, as both the production and consumption of poultry products are rather closed to external influences.

The monophasic variant of $S$. Typhimurium, S. 4,[5],12:i:-, characterised by the antimicrobial resistance to Ampicillin, Streptomycin, Sulphonamide, and Tetracycline (pattern ASSuT) is emerging and extensively circulating in Denmark, Italy, the United Kingdom and also recently in Greece $[11,23,24]$. In
Italy, S. 4,[5],12:i:-, showed a dramatic increase since 2003, both in humans and in animals farmed for food production, particularly pigs and bovines [25]. Also $S$. Napoli is an emerging serovar although it is not emerging homogenously over the whole EU, with most of the cases (87\%) reported between 2000 and 2006 having occurred in Italy, France, and Switzerland. It has been suggested that the environment can act as the main reservoir for $S$. Napoli, and from there this serovar can spill over to animals and humans [10].

Most serovars showed a marked seasonality, increasing over the summer months and peaking in August/ September, and then decreasing gradually. Although the reasons of this pattern are not entirely known, it may be related to the parallel Salmonella shedding trend in animal hosts, and/or insufficient refrigeration and mishandling of foods during the warm months $[26,27]$.

As expected, isolation rates were highest in children. This may be due to the greater proportion of symptomatic infections among the young but also to the higher propensity to take samples by paediatricians (i.e. detection bias) [27]. However, consistent with other studies $[10,11,27]$, we observed that cases with S. Typhimurium, S. 4,[5],12:i:-, or S. Napoli infection were most likely to be children aged $\leq 14$ years, whereas cases with S. Enteritidis, S. Derby, or S. Infantis infections were more likely to be adults aged $\geq 15$ years. This may be due to the different serovar-specific risk factors to which individuals are exposed at varying age groups [28].

This study is based on reported data from laboratories that are not homogenously distributed in the Italian territory; thus, there may be differences in representativeness of the data from different regions. It has been showed that the surveillance systems of northern regions of Italy are generally more sensitive in detecting cases of infectious gastroenteritis, leading to significantly higher notification rates of salmonellosis compared to the national average [9]. Moreover, diagnostic capacity for enteropathogens differs from laboratory to laboratory in Italy [29]. These may be the reasons as to why we observed that the isolation rates were considerably lower in the southern part of the country.

Regarding the selection of isolates included in our analyses, we deleted duplicates and most of the outbreakrelated cases in order to represent as much as possible the role of the different serovars without any 'artificial' replication of isolates due to outbreaks. Documented major outbreaks of human salmonellosis that occurred in Italy during the study period have concerned mainly S. Typhimurium [e.g. 30] and S. Enteritidis [e.g. 31].

In conclusion, Salmonella serotyping is useful for informing and addressing public health actions, providing data about the emerging serovars (which may 
reveal the presence of a previously unrecognised source of infection) and the efficacy of intervention measures.

We found that $S$. Enteritidis has decreased dramatically in Italy and that $S$. Typhimurium has become once more the most reported serovar as of 2000 . It is noteworthy that between 2000 and 2011, while S. Enteritidis and $S$. Infantis decreased, $S$. Typhimurium remained stable and S. 4,[5],12:i:-, S. Derby, and S. Napoli increased. This suggests that the applied control measures are not equally efficient against these serovars and that other sources of infection have probably become increasingly important (e.g. unconventional, wild and freerange animals, fruit and vegetables). Therefore, further investigation into the potential causes of spread of the emerging serovars, against which newly tailored control measures should be implemented, is warranted.

\section{References}

1. European Food Safety Authority (EFSA), European Centre for Disease Prevention and Control (ECDC). The European Union Summary Report on Trends and Sources of Zoonoses, Zoonotic Agents and Food-borne Outbreaks in 2010. EFSA Journal. 2012;10(3):2597. Available from: http://www.efsa.europa.eu/ en/efsajournal/doc/2597.pdf

2. Havelaar AH, Ivarsson S, Löfdahl M, Nauta MJ. Estimating the true incidence of campylobacteriosis and salmonellosis in the European Union, 2009. Epidemiol Infect. 2012;1-10.

3. Popoff MY, Bockemühl J, Gheesling LL. Supplement 2002 (no. 46) to the Kauffmann-White scheme. Res Microbiol. 2004;155(7):568-70.

http://dx.doi.org/10.1016/j.resmic.2004.04.005 PMid:15313257

4. Pires S, de Knegt L, Hald T. Estimation of the relative contribution of different food and animal sources to human Salmonella infections in the European Union, Question No EFSA-Q-2010-00685. Parma: European Food Safety Agency. [Accessed $18 \mathrm{Sep} 2012$ ]. Available from: http://www.efsa. europa.eu/en/supporting/doc/184e.pdf

5. Scuderi G. A review of the Salmonellosis surveillance systems in Italy: evolution during the course of time within the international framework. Eur J Epidemiol. 2000;16(9):861-8 http://dx.doi.org/10.1023/A:1007698200106 PMid:11297229

6. Fantasia M, Filetici E, Arena S, Mariotti S. Serotype and phage type distribution of salmonellas from human and non-human sources in Italy in the period 19731995. Eur J Epidemiol. 1998;14(7):701-10. http://dx.doi. org/10.1023/A:1007434001440 PMid:9849832

7. Fisher IS. The Enter-net international surveillance network - how it works. Euro Surveill. 1999;4(5):pii=73. Available from: http://www.eurosurveillance.org/ViewArticle. aspx?Articleld $=73$

8. Carrieri MP, Salmaso S, Bella A, D’Ancona F, Demicheli $\mathrm{V}$, Marongiu C, et al. Evaluation of the SIMI system, an experimental computerised network for the surveillance of communicable diseases in Italy. Eur J Epidemiol. 2000;16(10):941-7. http://dx.doi.org/10.1023/A:1011094116944 PMid:11338126

9. Mughini-Gras L, Graziani C, Biorci F, Pavan A, Magliola R, Ricci A, et al. Surveillance of acute infectious gastroenteritis (1992-2009) and food-borne disease outbreaks (1996-2009) in Italy, with a focus on the Piedmont and Lombardy regions. Euro Surveill. 2012;17(8):pii=20098. Available from: http:// www.eurosurveillance.org/ViewArticle.aspx?Articleld $=20098$ PMid:22401508

10. Fisher IS, Jourdan-Da Silva N, Hächler H, Weill FX, Schmid H, Danan C, et al. Human infections due to Salmonella Napoli: a multicountry, emerging enigma recognized by the Enter-net international surveillance network. Foodborne Pathog Dis. 2009;6(5):613-9. http://dx.doi.org/10.1089/fpd.2008.0206 PMid:19534593

11. Busani L, Graziani C, Battisti A, Franco A, Ricci A, Vio D, et al. Antibiotic resistance in Salmonella enterica serotypes Typhimurium, Enteritidis and Infantis from human infections, foodstuffs and farm animals in Italy. Epidemiol Infect. 2004;132(2):245-51.
http://dx.doi.org/10.1017/So950268803001936 PMid:15061499 PMCid:PMC 2870100

12. Cuzick J. A Wilcoxon-type test for trend. Stat Med. 1985;4(1):87-90. http://dx.doi.org/10.1002/sim.4780040112 PMid:3992076

13. Bäumler AJ, Hargis BM, Tsolis RM. Tracing the origins of Salmonella outbreaks. Science. 2000;287(5450):50-2. http://dx.doi.org/10.1126/science.287.5450.50 PMid:10644222

14. Collard JM, Bertrand S, Dierick K, Godard C, Wildemauwe C, Vermeersch K, et al. Drastic decrease of Salmonella Enteritidis isolated from humans in Belgium in 2005, shift in phage types and influence on foodborne outbreaks. Epidemiol Infect. 2008;136(6):771-81.

http://dx.doi.org/10.1017/So95026880700920X PMid:17645812 PMCid:PMC 2870868

15. Marcus R, Rabatsky-Ehr T, Mohle-Boetani JC, Farley M, Medus $C$, Shiferaw B, et al. Dramatic decrease in the incidence of Salmonella serotype Enteritidis infections in 5 FoodNet sites: 1996-1999. Clin Infect Dis. 2004;38 Suppl 3:S135-41. http:// dx.doi.org/10.1086/381579 PMid:15095182

16. Cogan TA, Humphrey TJ. The rise and fall of Salmonella Enteritidis in the UK. J Appl Microbiol. 2003;94 Suppl:114S$119 \mathrm{~S}$.

http://dx.doi.org/10.1046/j.1365-2672.94.S1.13.x PMid:12675943

17. Hendriksen RS, Vieira AR, Karlsmose S, Lo Fo Wong DM, Jensen $A B$, Wegener $H C$, et al. Global monitoring of Salmonella serovar distribution from the World Health Organization Global Foodborne Infections Network Country Data Bank: results of quality assured laboratories from 2001 to 2007 . Foodborne Pathog Dis. 2011;8(8):887-900. http://dx.doi.org/10.1089/ fpd.2010.0787 PMid:21492021

18. Centers for Disease Control and Prevention (CDC). Outbreaks of Salmonella serotype Enteritidis infection associated with eating raw or undercooked shell eggs-United States, 1996-1998. MMWR Morb Mortal Wkly Rep. 2000;49(4):73-9. PMid:10706440

19. Council of the European Union. Council Directive $92 / 117 /$ EEC of 17 December 1992 concerning measures for protection against specified zoonoses and specified zoonotic agents in animals and products of animal origin in order to prevent outbreaks of food-borne infections and intoxications. Official Journal of the European Union. Luxembourg: Publications Office of the European Union. 15.03.1993:L62/38. Available from: http://eurlex.europa.eu/LexUriServ/LexUriServ.do?uri=0J:L:1993:062:00 38:0048:EN:PDF

20. European parliament and council of the European Union. Directive 2003/99/EC of the European Parliament and of the Council of 17 November 2003 on the monitoring of zoonoses and zoonotic agents, amending Council Decision 90/424/EEC and repealing Council Directive 92/117/EEC. Official Journal of the European Union. Luxembourg: Publications Office of the European Union. 12.12.2003:L325/31. Available from: http:// eur-lex.europa.eu/LexUriServ/LexUriServ.do?uri=0J:L:2003:32 5:0031:0040:EN:PDF

21. Waldram A, Inns T, Willson D, Lane C, Gorton R. The changing profile of Salmonella serovars in England \& Wales. Abstract presented at: European Scientific Conference on Applied Infectious Disease Epidemiology; 2011; Stockholm: European Centre for Disease Prevention and Control (ECDC); 2011. Available from: http://ecdc.europa.eu/en/ESCAIDE/Materials/ Documents/ESCAIDE-2011-Abstract\%20Book.pdf

22. Capua I, Marangon S. The avian influenza epidemic in Italy, 1999-2000: a review. Avian Pathol. 2000;29(4):289-94. http://dx.doi.org/10.1080/03079450050118403 PMid:19184817

23. Lucarelli C, Dionisi AM, Torpdahl M, Villa L, Graziani C Hopkins K, et al. Evidence for a second genomic island conferring multidrug resistance in a clonal group of strains of Salmonella enterica serovar Typhimurium and its monophasic variant circulating in Italy, Denmark, and the United Kingdom. J Clin Microbiol. 2010;48(6):2103-9. http://dx.doi.org/10.1128/ JCM.01371-09 PMid:20410351 PMCid:PMC2884514

24. Mandilara G, Lambiri M, Polemis M, Passiotou M, Vatopoulos A. Phenotypic and molecular characterisation of multiresistant monophasic Salmonella Typhimurium $(1,4,[5], 12: \mathrm{i}:-)$ in Greece, 2006 to 2011. Euro Surveill. 2013;18(22):pii=20496. Available from: http://www.eurosurveillance.org/ViewArticle. aspx?Articleld=20496 PMid:23787078

25. Centro di referenza nazionale per le salmonellosi. Enter-Vet Report 2009. Legnaro: Istituto Zooprofilattico Sperimentale delle Venezie; 2011. Available from: http://www.izsvenezie.it/ images/stories/Pdf/Salmonelle/report_entervet_2009new.pdf

26. Callaway TR, Edrington TS, Anderson RC, Byrd JA, Nisbet DJ. Gastrointestinal microbial ecology and the safety of our food supply as related to Salmonella. J Anim Sci. 2008;86(14 Suppl):E163-72. http://dx.doi.org/10.2527/jas.2007-0457 PMid:17878279 
27. Olsen SJ, Bishop R, Brenner FW, Roels TH, Bean N, Tauxe $\mathrm{RV}$, et al. The changing epidemiology of Salmonella: trends in serotypes isolated from humans in the United States, 1987-1997. J Infect Dis. 2001;183(5):753-61. http://dx.doi. org/10.1086/318832 PMid:11181152

28. Doorduyn Y, Van Den Brandhof WE, Van Duynhoven YT, Wannet WJ, Van Pelt W. Risk factors for Salmonella Enteritidis and Typhimurium (DT104 and non-DT104) infections in The Netherlands: predominant roles for raw eggs in Enteritidis and sandboxes in Typhimurium infections. Epidemiol Infect. 2006;134(3):617-26. http://dx.doi.org/10.1017/ So950268805005406 PMid:16638166 PMCid:PMC2870426

29. Graziani C, Mughini Gras L, Luzzi I, Ricci A, Busani L. Capacity for routine laboratory diagnosis of enteric pathogens in Italy. Abstract presented at: European Scientific Conference on Applied Infectious Disease Epidemiology; 2011; Stockholm: European Centre for Disease Prevention and Control (ECDC); 2011. Available from: http://ecdc.europa.eu/en/ESCAIDE/ Materials/Documents/ESCAIDE-2011-Abstract\%20Book.pdf

30. Luzzi I, Galetta P, Massari M, Rizzo C, Dionisi AM, Filetici $\mathrm{E}$, et al. An Easter outbreak of Salmonella Typhimurium DT $104 \mathrm{~A}$ associated with traditional pork salami in Italy. Euro Surveill. 2007;12(4):pii=702. Available from: http:// www.eurosurveillance.org/ViewArticle.aspx?Articleld $=702$ PMid:17991384

31. Romani C, Nicoletti P, Buonomini MI, Nastasi A, Mammina C. Reinterpreting a community outbreak of Salmonella enterica serotype Enteritidis in the light of molecular typing. BMC Public Health. 2007;7:237. http://dx.doi.org/10.1186/14712458-7-237 PMid:17825103 PMCid:PMC1995211 